\title{
TEXTOS-LEITURA, EFEITO DE MONTAGEM: EVENTO COMPARATISTA
}

Nabil Araújo*

RESUMO: Este texto oferece uma leitura de minha tese de doutorado - O evento comparatista: na história da crítica / no ensino de literatura (2013) -, menos para simplesmente apresentá-la ao leitor do que para convidá-lo a empreender sua própria leitura da mesma.

PALAVRAS-CHAVE: Texto-leitura; montagem; evento comparatista; história da crítica; ensino de literatura.
* nabil.araujo@gmail.com

Doutorado em Teoria da Literatura e Literatura Comparada pela Faculdade de Letras da UFMG.

ABSTRACT: This text offers a reading of my doctora thesis - O evento comparatista: na história da crítica / no ensino de literatura (2013) -, less to simply present it to the reader than to invite him/her to undertake his/ her own reading of it.

KEYWORDS: Text-as-reading; montage; comparatist event; history of criticism; literature teaching. 
1. BARTHES. Écrire la lecture, p. 34.

2. ARAÚJO. O evento comparatista: na história da crítica / no ensino de literatura. $379 \mathrm{f}$. Tese (Doutorado em Literatura Comparada) - Programa de PósGraduação em Estudos Literários da Faculdade de Letras da UFMG, Belo Horizonte, 2013.
Apoiando-me na definição que Roland Barthes ofereceu acerca do que ele próprio havia feito em $S / Z(1970)$ - ocasião na qual esclarece haver tentado, no referido livro, escrever sua própria leitura de Sarrasine de Balzac, denominando, então, o produto desse trabalho, de "texte-lecture" -, ${ }^{1}$ chamo justamente de texto-leitura o que ora se apresenta a título de tese, ${ }^{2}$ por também se tratar, aí, fundamentalmente, da escrita de uma leitura, ou melhor, da escrita de leituras, mais especificamente, de três leituras: trata-se, pois, de um tríptico leitural, composto, na verdade, por três textos-leitura justapostos, cada um deles focado num objeto de leitura determinado, num livro determinado, a saber: em Death of a discipline (2003) de Gayatri Spivak, o primeiro texto-leitura; em Theor of literature (1949) de René Wellek e Austin Warren, o segundo; em Practical criticism (1929) de I. A. Richards, o terceiro.

Como se vê, os textos aí lidos são três destacados exemplares da teoria literária anglófona. $\mathrm{O}$ fato de que os livros a em foco estejam escritos em inglês e sejam lidos, então, nessa sua língua original afasta de antemão qualquer pretenso sentimento de co-pertencimento linguístico-cultural entre o leitor e os autores dos textos lidos, fazendo com que os textos-leitura em questão assumam-se, na verdade, e desde o início, como deliberadas traduções lusófonas dos textos que neles são lidos; e isso não apenas quanto aos três principais objetos de leitura, mas também quanto aos inúmeros outros textos em língua estrangeira, em inglês ou outras línguas (majoritariamente em francês e alemão, eventualmente em italiano e espanhol), que porventura aí se vejam mobilizados por ocasião e em função das leituras principais.

Que os referidos textos se vejam todos, então, via de regra, lidos/traduzidos em suas línguas originais não implica que as traduções lusófonas já existentes desses textos sejam aí simplesmente ignoradas: em existindo tais traduções (em muitos casos, não existem), invariavelmente são consultadas, encontrando-se devidamente indicadas nas referências bibliográficas. A tradução própria que então se dá a ler nesses casos não se empreende, portanto, num trato direto e imediato única e exclusivamente com o próprio texto estrangeiro traduzido, mas em franco diálogo com essas traduções outras, das quais ela discrepa, diverge, discorda em aspectos e graus variados, diálogo esse que, apesar de constante, tende a permanecer implícito (ficando a cargo do leitor interessado o eventual cotejo de traduções).

Essa oposicionalidade em face de abordagens outras de um mesmo texto, se permanece implícita no nível mais estritamente tradutório dos textos-leitura em questão, vem com pletamente à tona no nível mais marcadamente analitico-hermenêtico dos mesmos: em cada um deles, a leitura do texto principal anuncia-se e realiza-se em aberta contraposição a 
uma leitura já instituída do mesmo texto, desenvolvendo-se, assim, ao modo de uma contraleitura, de uma desleitura desse texto principal. No texto-leitura inicial, traz-se à cena, com efeito, o primeiro (e, ao que se saiba, único) artigo acadêmico de fôlego dedicado a Death of a discipline no Brasil, publicado na Revista Brasileira de Literatura Comparada em 2005, para a partir dele encaminhar-se opositivamente uma leitura outra do livro de Spivak. Nos textos-leitura seguintes, essa leitura outra, seja de Theory of literature, seja de Practical criticism vê-se encaminhada em franca contraposição ao estatuto de "classicidade" desses livros no campo dos estudos literários, grande empecilho a que os mesmos sejam verdadeiramente lidos na contemporaneidade. Essa contraleitura/desleitura de Spivak, de Wellek e Warren, de Richards então em curso se vê, além disso, desdobrada, dir-se-ia "en abyme", em relação a certos textos que eles próprios se põem a ler em seus respectivos livros: Spivak lendo Politiques de l'amitié de Derrida em Death of a discipline; Wellek e Warren lendo a terceira Critica kantiana [Kritik der Urteilskraft] em Theory of literature; Richards lendo os textos críticos de seus alunos (que, por sua vez, estão a ler poemas de John Donne, D. H. Lawrence, Gerald Manley Hopkins, entre outros) em Practical criticism.

Mas que acontece, afinal, nessas contraleituras/desleituras dos referidos textos teóricos estrangeiros? Retomando a célebre analogia de Wolfgang Iser entre leitura e música, segundo a qual: "por um lado, o texto é apenas uma partitura [nur eine Partitur], e, por outro lado, são as capacidades individualmente diferenciadas dos leitores [die individuell verschiedenen Fähigkeiten der Leser] que instrumentam a obra", vem a calhar o que Michael Jarrett pondera acerca da relação da música clássica, por um lado, e do jazz, por outro, com "ordem da notação" [the order of notation]. Enquanto "o desenvolvimento da música clássica é convencionalmente entendido como dependente da escrita, especialmente das inscrições ideográficas da notação padrão”, o jazz, por sua vez, "é representado como alheio à ordem da notação", aquilo que lhe é essencial sendo "tradicionalmente visto como intranscrevível”, observa Jarrett, retrucando: "Mas pense novamente. O jazz é comumente entendido como um método gerativo de fazer música a partir de música. É uma metamúsica votada à exploração sistemática das condições que dão origem à inscrição. Mais verbo do que substantivo, durante anos o jazz tem sido visto como um paradigma de invenção". ${ }^{4} \mathrm{O}$ jazz não seria, pois, rigorosamente falando, alheio à ordem da notação - isto é, à escrita -, mas se relacionaria com ela diferentemente do que o faz a música clássica, algo concebido por Jarrett nos termos de uma diferença fundamental entre os dois regimes de leitura implicados pelos dois referidos regimes de musicalidade (o clássico e o jazzístico): "aprender os métodos da música clássica exige que se aprenda a reler (o que já foi escrito)", ele diz, acrescentando: "Aprender os
3. ISER. Der Akt des Lesens, p. 177.

BELO HORIZONTE

v. 19

N. 2

A60.-OUT. 2013

ARAÚJO. Textos-leitura, efeito de montagem: 0 evento comparatista

P. $238-251$ 
5. JARRETT. Drifting on a read, p. 5.

6. Baseio-me, para tanto, sobretudo em Piettre (1996). métodos do jazz exige que se aprenda a ler perversamente (o já escrito)"; e ainda: "Reler é a essência da erudição cuidadosa [careful scholarship]; a leitura perversa ou aberrante é a essência da criatividade, uma habilidade que nossas instituições educacionais, em sua maioria, têm se negligenciado a ensinar". ${ }^{5}$

Nesses termos, agrada-me conceber as desleituras em jogo nos textos-leitura em questão como verdadeiras jazz sessions: performances de leituras aberrantes de determinadas "partituras" das quais já se dispõe de um padrão prévio de leitura - dir-se-ia: "clássico" -, em vista do qual as referidas performances instituem-se como desvios ou afastamentos (o verbo latino aberrare - em português: aberrar - significa, em seu sentido próprio, justamente "desviar-se do caminho", "afastar-se"). Desvios/afastamentos, bem entendido, nos quais algo ocorre, ou é criado.

Mas como se daria, afinal, essa criação a partir da aberrância? Para respondê-lo, lanço mão de uma outra analogia, dessa vez com o campo da física, mais especificamente com o de uma filosofia da ciência baseada nos trabalhos de Ilya Prigogine - Prêmio Nobel de Química em 1977 - acerca da termodinâmica do "longe do equilíbrio" e das chamadas "estruturas dissipativas". ${ }^{6}$ Prigogine mostra, em suma, que não é apesar do aumento da entropia (dissipação irreversível da energia) nas relações de um sistema com o meio externo que uma nova ordem, uma nova estrutura organizada então emerge na natureza, e sim justamente em função desse aumento. Mais do que mera compensação para o desequilíbrio entrópico de um sistema dissipativo, a emergência de estruturas organizadas teria no mesmo, na verdade, suas condições de possibilidade (e no equilíbrio sistêmico, em contrapartida, um impedimento): "O equilíbrio maximal de um sistema constitui um estado limite interditando o aparecimento de uma nova ordem qualquer. Inversamente, a irreversibilidade e o desequilíbrio são, por outro lado, a condição da aparição de uma ordem".7

Assim, se Jarrett reserva a prerrogativa da "criatividade" em música ao modo jazzístico de leitura - em detrimento do modo clássico, no qual a leitura se daria sempre como releitura -, com Prigogine, vê-se atrelada à impredizibilidade/ irreversibilidade da evolução de um sistema dissipativo distante do equilíbrio a prerrogativa da criação de novas estruturas organizadas na natureza, as "estruturas dissipativas". Em ambos os casos, a trajetória dita "criativa" - isto é, aquela que dará vazão ao novo num determinado terreno - é concebida como um desvio, um descaminho em face de um estado de coisas previamente instituído e estabilizado. Numa analogia possível entre a leitura-como-instrumentação-de-uma-partitura e os fenômenos termodinâmicos na natureza, dir-se-ia que as desleituras em jogo nos textos-leitura aqui
7. PIETTRE. Philosophie et science du temps, p. 84. 
apresentados se afiguram justamente como trajetórias leiturais dissipativas à contracorrente de determinadas tendências estabilizadas/ institucionalizadas de leitura acadêmica, trajetórias cuja aberrância entrópica em face de tais tendências, a um só tempo impredizivel e irreversivel, acarreta, não obstante, a "aparição de uma nova ordem".

É desse modo que a desleitura de Death of a discipline, no primeiro texto-leitura, se se confunde, numa trajetória dissipativa que faz recuar de Spivak a Wellek, de Wellek aos "pais fundadores" do comparatismo na França, com nada menos do que o desmantelamento do discurso comparatista ocidental em sua pretensão disciplinar (ponto máximo de entropia), faz ascender, não obstante, na verdade por efeito dessa própria dissipação, um grande "evento" implicado pela emergência do discurso comparatista, dito o "evento comparatista”, em função do qual se tornam patentes, a um só tempo, a historicidade constitutiva da crítica literária e a natureza do gesto historiográfico a desvendá-la (isto vindo à tona ao modo de uma "nova ordem"). No segundo texto-leitura, o percurso leitural que faz remontar o grande manua de teoria da literatura do século XX - aquele que, mais do que qualquer outro, concorreu para delimitar e configurar internacionalmente todo um campo disciplinar e acadêmico, dito "teórico", no âmbito dos estudos literários - ao livro em face do qual o referido manual se institui como resposta o percurso leitural, portanto, que faz remontar a Theory of literature (1949) de Wellek e Warren à Kritik der Urteilskraft (1790) de Kant, no próprio movimento pelo qual desmantela a pretensão epistemológico-metodológica que alimenta não somente o programa teórico de Wellek e Warren mas também programas teóricos rivais, logra elucidar as intrincadas condições de emergência da teoria da literatura na modernidade crítica. Por fim, no terceiro texto-leitura, o percurso leitural pelo qual se vê desmantelado o programa richardsiano de uma pedagogia literária pautada por uma "crítica prática" - aquele que se encontra na base da institucionalização escolar/acadêmica, no século passado, dos "literary studies" no mundo anglófono - é o mesmo percurso que acarreta, por efeito dissipativo, uma compreensão renovada do ato crítico, a demandar, ela própria, uma nova pedagogia literária.

Se se pode dizer, pois, que em cada um dos três casos uma trajetória leitural dissipativa logra acarretar, em sua impredizibilidade e irreversibilidade mesmas, algo como a "aparição de uma nova ordem", seria preciso igualmente reconhecer o quanto - ao menos essa é a sensação a posteriori - tal "aparição", fenômeno inegavelmente contingente, reveste-se de um caráter necessário. Seria preciso pensar, então, esse cruzamento de contingência e necessidade no próprio coração da leitura-como-instrumentação-de-uma-partitura. 
8. DERRIDA. La pharmacie de Platon, p. 79-83.

9. DERRIDA. Ponctuations, p. 448.
Para tanto, evoco a célebre leitura-escrita do Fedro levada a cabo por Derrida em “A farmácia de Platão". Se a execução derridiana da velha partitura platônica quer-se a si própria, por um lado, uma nova execução, ela também se quer, num sentido importante, a primeira: aquela mesma que, pela primeira vez, não se limita a ver (perceber) o texto-partitura do Fedro mas se põe, de fato, a tocá-lo - e a tocá-lo como deve ser, isto é, seguindo "o fio dado", outrora ignorado por outros leitores. ${ }^{8}$ A desleitura derridiana do Fedro se dá, assim, a um só tempo como aberrância criativa e como desvelamento da "textura" (da "lei" e da "regra" textuais) que teria sido encoberta pelo sobretecido de leituras equivocadas.

Mas se o que então emerge de uma tal desleitura emerge, pois, ao modo de uma verdade revelada, ou melhor, desvelada, é preciso admitir não se encontrar aí em jogo, nesse desvelamento, nada como um método - o desvelamento em questão afigurando-se como um acontecimento a um só tempo impredizível e irreversível - e, como tal, irreprodutível. Isso torna o acontecimento de leitura em questão - e outros como ele - irredutível à figura clássica da "tese", como admitirá, aliás, Derrida, paradoxalmente no discurso de sua própria "defesa de tese" (1980), no qual pondera que a certa altura de sua trajetória intelectual: "Era já claro para mim que o andamento de minhas pesquisas não mais poderia se submeter às normas clássicas da tese”. ${ }^{9}$ Mais à frente:
A expansão desses textos ocupados de textualidade podia parecer anamórfica ou labiríntica, uma e outra, mas o que a tornava quase insustentável, em particular como tese, era menos a multiplicidade dos conteúdos, das conclusões e das posições demonstrativas do que, parece-me, os atos de escrita e a cena performativa aos quais eles deviam dar lugar e dos quais permaneciam inseparáveis, logo dificilmente representáveis, transportáveis e traduzíveis numa outra forma. ${ }^{10}$

Faz-se preciso, assim, reconhecer o mesmo em relação aos textos-leitura aqui apresentados, também eles implicando "atos de escrita", irreversíveis como tais (como atos que são), cujos "resultados", rigorosamente inseparáveis de tais atos, permaneceriam igualmente irreversíveis, isto é, não-reversíveis (não-representáveis, não-transportáveis, não-traduzíveis) num conteúdo tético em si mesmo e por si mesmo generalizável. O que se quer chamar aqui de tese, "a" tese, não poderia residir, portanto, no nível de tais "resultados", nem no de sua mera soma, operação a rigor impossível, já que os mesmos permaneceriam irreversíveis/irredutíveis também uns em relação aos outros (posto que atrelados a três atos de escrita irreversíveis/irredutíveis entre si).

O que se quer chamar aqui de tese avulta, na verdade, por efeito do choque entre os três textos-leitura em questão, gerado por sua justaposição como textos-leitura numa determinada sequência. A analogia mais conveniente quanto a isso não há
10. DERRIDA. Ponctuations, p. 454-455.

IM TESE

BELO HORIZONTE

v. 19

N. 2

AG0.-OUT. 2013

ARAÚJO. Textos-leitura, efeito de montagem: 0 evento comparatista

P. $238-251$ 
11. EISENSTEIN. Word and image, p. 7-8.

12. EISENSTEIN. Word and image, p. 11. de se estabelecer nem com o campo musical nem com o da física, mas com o do cinema, mais especificamente com a teoria da montagem desenvolvida por Sergei Eisenstein nas décadas de 1920 e 1930, segundo a qual, em suma:

a justaposição de dois planos independentes pela união dos mesmos não tanto se assemelha a uma simples soma de um plano mais outro - quanto realiza uma criação. Assemelha-se a uma criação - ao invés de a uma soma de suas partes - pela circunstância de que em toda justaposição como essa $o$ resultado é qualitativamente diferenciável de cada elemento componente visto separadamente. ${ }^{11}$

\section{Eisenstein prossegue:}

Num tal caso, cada peça da montagem não mais existe como algo irrelacionado, mas como uma dada representação particular do tema geral, que penetra, em igual medida, todas as peças-plano. A justaposição desses detalhes parciais numa dada estrutura de montagem chama à vida e traz à luz aquela qualidade geral em que cada detalhe teve participação e que une todos os detalhes numa totalidade, nomeadamente, naquela imagem generalizada na qual o criador, seguido pelo espectador, experiencia o tema.$^{12}$

A essa concepção da montagem cinematográfica, não seria equivocado tomá-la como uma apresentação do que se encontra em jogo também na justaposição dos três textos-leitura aqui em foco, bastando, quanto a isso, substituir "tema" por tese, "criador" e "espectador" por, respectivamente, autor e leitor - desta forma: A justaposição desses detalhes parciais (os textos-leitura) numa dada estrutura de montagem chama à vida e traz à luz aquela qualidade geral em que cada detalhe teve participação e que une todos os detalhes numa totalidade, nomeadamente, naquela imagem generalizada na qual o autor, seguido pelo leitor, experiencia a tese. Em suma, cada um dos três eventos trazidos à tona, à guisa de novidades dissipativas, pelas três referidas desleituras, apresentar-se-iam, nesse caso, como os microeventos que, justapostos, dão a ver o macroevento pelo qual se experiencia "a tese": o "evento comparatista", em toda a sua amplitude e significação.

Não é outro, portanto, senão o mesmo evento que no primeiro texto-leitura é chamado comparatista aquele que parece ressurgir nos outros dois textos-leitura, ainda que a cada um desses aparentes ressurgimentos ele se veja consideravelmente ampliado, reconfigurado, repotencializado, de modo que a visão final do "evento comparatista" daí emergente não se confunde, a rigor, com nenhuma de suas manifestações particulares nem com a mera soma dessas manifestações, mas, antes, com uma síntese cognitiva, ela própria irredutível a qualquer das manifestações particulares que lhe servem de insumo.

EM TESE

BELO HORIZONTE

v. 19

N. 2

AG0.-OUT. 2013

ARAÚJO. Textos-leitura, efeito de montagem: 0 evento comparatista

P. $238-251$ 
Eis, a seguir, uma tentativa de explicitar essa síntese, como processo e como produto final (dir-se-ia: conteúdo tético, "a tese").

A inexistência de algo como uma comparação literária propriamente comparatista, isto é, que caracterizasse, de forma necessária e suficiente, aquela atividade que se chamaria então, "Literatura Comparada", e apenas ela - em contraste, bem entendido, com a comparação literária praticada pela crítica tout court-, tal inexistência, uma vez revelada, nos dá a ver como miragem tanto a disciplinaridade do comparatismo, instituída na passagem do século XIX para o XX na França, quanto o subsequente desenvolvimento transnacional do discurso comparatista como história disciplinar que se estende aos nossos dias. Tal miragem só pôde manter-se e desenvolver-se como tal no curso de tão longo tempo em função do sistemático recalcamento justamente da questão da comparação, do "problema da comparabilidade" (Culler) que assombrava os pais fundadores da pretensa disciplina - Baldensperger, Van Tieghem, Carré, Guyard - e que eles contribuíram decisivamente para escamotear ao imbuir o comparatismo de parâmetros curriculares, metodológicos, pedagógicos, sobretudo na forma de manuais acadêmicos.
De volta, contudo, com isso em mente, ao discurso de fundação da Littérature Comparée como ramo ou subdisciplina da moderna História da Literatura - implicando, pois, uma comparação literária de cunho eminentemente histórico contraposta à comparação literária de cunho eminentemente retórico praticada pela crítica dita "clássica" (isto é, "pré-moderna”) -, avulta, então, o grande insight ensejado por essa comparação aí em jogo entre modos distintos de comparação literária: o da comparatividade inerente a toda crítica; o de que toda atividade crítica é inerentemente comparativa, e isso por sua própria natureza: criticar (do grego krinein: "julgar") implica necessariamente comparar; o de que todos os modelos de leitura crítica são, portanto, modelos de comparação como tais comparáveis entre si. $\mathrm{O}$ discurso do comparatismo emerge, pois, em seu caráter de acontecimento, ao modo do do surgimento de uma pretensa (sub)disciplina comparatista a ser institucionalizada como tal (algo que, não obstante, acabou acontecendo sob a forma da Literatura Comparada), mas a da oposição entre duas perspectivas divergentes de comparação crítica - uma retoricista e outra historicista no próprio alicerce do edifício crítico (a instituir-se) no século XIX. Essa oposição implica uma comparatividade (de perspectivas críticas rivais) antes da comparação, comparatividade da qual dependeriam, aliás, os próprios princípios da prática crítico-comparativa por vir. Não havendo nada, a que se poderia chamar uma consciência comparatista: não a 
rigor, anterior a essa comparatividade originária, por assim dizer, nenhum princípio ou baliza comparativa que de fato ou de direito a antecedesse (a comparatividade tendo começado desde sempre), vê-se instaurada, aí, no caso da oposição entre as perspectivas críticas em questão, uma instância de indecidibilidade.

Mas se a decisão por um dos dois lados fez-se necessária (apesar de impossível) sempre que se tratou, por exemplo de pôr em funcionamento um pretenso modelo ou sistema de comparação crítica dito "moderno" - em detrimento de um modelo ou sistema dito "clássico" -, então é preciso reconhecer nessa decisão a partir de um horizonte de indecidibilidade o verdadeiro "nascimento da crítica". A consciência comparatista confunde-se, assim, em suma, com uma tomada de consciência, ao modo de um desvelamento, da própria historicidade da crítica: da conjuntura na qual uma perspectiva de comparação crítica emerge/institui-se em necessária oposição a uma perspectiva rival, inexistindo, nesse momento oposicional anterior à consolidação de um modelo ou sistema crítico propriamente dito, qualquer tipo de baliza epistemológica externa (à própria oposição) que pudesse fundamentar a preferência por essa ou aquela perspectiva, revelando-se, com isso, o fundo sem fundo, o solo de indecidibilidade no qual se dá o nascimento da crítica.
Inicialmente concebido como complemento subserviente da teoria oitocentista da história literária, o discurso do comparatismo implica, na verdade, em seu caráter de acontecimento, uma consciência comparatista que põe a nu nada menos do que a historicidade da crítica, suas condições históricas de (im)possibilidade. A consciência comparatista (e tudo o que ela dá a ver em termos da historicidade recalcada da crítica) avulta por efeito da emergência da teoria francófona do comparatismo, ou melhor, por efeito de um acontecimento especial identificável como tal por ocasião dessa emergência: algo como a mise-en-comparation de diferentes perspectivas de comparação crítica, uma metacomparação, portanto, ou uma comparação de segunda ordem. Esse acontecimento reveste-se de um significado e de uma importância tais a ponto de se poder considerá-lo um evento de primeira grandeza na história dos estudos literários ocidentais: o evento comparatista. Ele demarca não simplesmente a referida emergência de uma teoria francófona do comparatismo, mas aquilo mesmo que, nessa emergência, implica uma espécie de excesso ou de exorbitância teórica não programada, algo que converte o discurso que se quereria, a princípio, mero complemento subserviente da teoria da história literária num perigoso suplemento dessa mesma teoria, ao modo de uma dobra teórica auto-reflexiva a desnudar as condições históricas de (im)possibilidade do empreendimento crítico historicista. 
Um tal evento mostra-se indissociável do dizer-evento (Derrida) que o traz à tona; a possibilidade (e a expectativa) de que o dizer-evento comparatista venha a se repetir anuncia-se, assim, como a condição de possibilidade de uma historiografia da crítica que, sob a forma de reiterados acontecimentos metacomparativos historio-gráficos (por vir), reiteradamente nos dê a ver a historicidade da crítica recalcada pela periódica institucionalização/naturalização de protocolos de leitura no âmbito dos estudos literários.

É mesmo um lance historiográfico dessa natureza que se deixa reconhecer quando, sob o mote da lógica gadameriana da pergunta e da resposta, vem-se a desvelar o mais importante manual de teoria da literatura do século XX - a Theory of literature (1949), de René Wellek e Austin Warren - como uma resposta a Kant, isto é, à questão da fundamentação da crítica estético-literária implicada pela "subjetivação radical" (Gadamer) do juízo estético operada na Kritik der Urteilskraft [Crítica da Faculdade do Juízo] (1790), mas uma resposta eminentemente kantiana a Kant, já que autoconcebida como o desenvolvimento de uma "sugestão" contida, segundo Wellek, na própria Kritik der Urteilskraft, a saber: a analogia entre "arte" e "organismo", a qual servirá, então, de alicerce para teoria crítica organicista-formalista promulgada pelos autores da Theory. O problema é que tal resposta não pode ser tomada, simplesmente, como "a" resposta kantiana a Kant, já que ela emerge, na verdade, em face de duas outras respostas já existentes, aventadas como tais na própria Theory, e que também se instituem como respostas kantianas a Kant, isto é, a exemplo da própria Theory, como desenvolvimentos de diferentes "sugestões" na Kritik der Urteilskraft: o primeiro deles, o deslocamento romântico-idealista do foco do interesse estético do "gosto" para o "gênio", seguido da naturalização e da cientificização da "estética do gênio" sob a égide da ideologia positivista, num sentido importante estimulada pelo próprio Kant; o segundo, o desenvolvimento do conceito de "gênio" para um abrangente conceito neokantiano de "vida", e, a partir de Dilthey e sua "crítica da razão histórica", para o conceito de "vivência" como fundamento último das ciências do espírito.

As três respostas em questão deixam-se apreender, então, como três respostas possíveis ao mesmo "horizonte da pergunta" (Gadamer), tendo mesmo, na verdade, cada uma delas e todas as três, sua possibilidade condicionada pelo advento do que se poderia chamar, no âmbito geral da moderna tripartição kantiana das "esferas de valor" - a cognitiva, a moral e a estética-, de modernidade crítica: aquela conjuntura na qual o crítico estético-literário tem reservados a si, e como nunca antes, um domínio e uma jurisdição que lhe seriam próprios e exclusivos, ao mesmo tempo em que se vê privado do fundamento necessário à tomada de posse do referido 
domínio e ao exercício legítimo da referida jurisdição - fundamento esse que, portanto, deve ser doravante buscado, conquistado pelo crítico, e por ele estabelecido, finalmente, de maneira consensual. Aí reside o grande problema: as três respostas revelam-se, de fato, respostas possíveis mas não compossiveis a essa busca caracteristicamente moderna pelo fundamento crítico, isto é, elas não são, como respostas, concomitantemente possíveis, mas mutuamente excludentes, e isso em sua origem mesma: a própria emergência de cada uma delas como resposta implica justamente a negação das demais como respostas. Não há resposta, nessa conjuntura, que não se institua como contra-resposta.

$\mathrm{Na}$ ausência de um critério epistemologicamente neutro de escolha entre as possibilidades discrepantes de resposta aí em embate, a decisão, qualquer que seja ela, se faz incontornavelmente arriscada. $\mathrm{O}$ risco é permanente, pois, e, mesmo com ele, é preciso prosseguir, sob pena de não haver resposta. No percurso que vai de Königsberg (1790) a New Haven (1949), os intérpretes da terceira Crítica tiveram mesmo de se decidir entre possibilidades incompossíveis de respostas kantianas a Kant, decisão essa a um só tempo necessária e impossível: eis as condições de emergência da teoria da literatura na modernidade crítica.

Que a concretização vitoriosa de uma determinada possibilidade em detrimento de outra então se dê e se prolongue, nesse contexto, via de regra, por força de critérios e argumentos extrínsecos ao embate hermenêutico-epistemológico - embate que permanece, ele próprio, de um ponto de vista intrínseco, indecidível - torna especialmente vulnerável o consenso em torno da resposta que daí emerge, permanentemente assombrada por aquela incompossível possibilidade outra que ela tivera de negar e recalcar para se instituir e se legitimar como resposta. Não estranha, assim, que a resposta vitoriosa acabe sendo deposta dessa sua posição por um gesto idêntico àquele pelo qual ascendera à mesma: negação-do-outro e afirmação-de-si revelam-se as contrafaces necessárias e indissociáveis de um único e mesmo gesto auto-instituidor e autolegitimador no âmbito de uma querela do fundamento crítico.

Eis aí, portanto, consideravelmente complexificado, o estado de coisas anteriormente identificado com o evento comparatista: a criticidade dita "moderna" avultada em detrimento daquela dita "clássica" revela-se, agora, intrinsecamente heterogênea, implicando, para além da (a) perspectiva historicista (à qual se filiava a Littérature Comparée), pautada pelo "ponto de vista do gênio", também uma (b) perspectiva filológico-hermenêutica, focada na Erlebnis [vivência], e uma (c) perspectiva formalista, focada na arte como "organismo”. E à medida que a questão do fundamento crítico bem como a estrutura conflitual do responder a que ela dá

EM TESE

BELO HORIZONTE

v. 19

N. 2

A60.-OUT. 2013

ARAÚJO. Textos-leitura, efeito de montagem: 0 evento comparatista

P. $238-251$ 
ensejo - se deixa desvelar mesmo onde a princípio se diria que ela ainda não se coloca - na Antiguidade, isto é, na pré-modernidade -, bem como naquela conjuntura epocal na qual ela pretensamente não mais se coloca - isto é, a chamada pós-modernidade -, então se pode dizer que a estrutura indecidivelmente conflitual do responder (inerente ao evento comparatista) reveste-se, no que concerne à história da crítica, daquele aspecto universal que Gadamer se esforçou por atribuir ao fenômeno hermenêutico.

Isso que se desvela aí, no âmbito de uma historiografia da crítica literária, numa dimensão eminentemente diacrônica, vê-se reinstaurado, numa dimensão eminentemente sincrônica, quando da reencenação contemporânea (UFMG, 2009) da experiência pedagógica em teoria da literatura levada a cabo por I. A. Richards na Inglaterra dos anos 1920 e por ele imortalizada no hoje clássico Practical criticism (1929), livro fundador da moderna prática crítica no universo acadêmico/escolar anglófono. Por ocasião da referida reencenação, constatou-se que as diferentes e discrepantes leituras críticas de uma mesma narrativa literária produzidas pelos alunos ao longo do curso afiguravam-se, todas elas, possivelmente corretas, mas não compossivelmente corretas, já que mutuamente excludentes entre si. Uma escolha era assim requerida: uma decisão entre as diversas possibilidades de leitura crítica correta da narrativa em questão. ${ }^{13}$
Ora, uma leitura crítica não pode, a rigor, afigurar-se "correta” senão à luz de um dado princípio de correção, daquele princípio epistemológico-axiológico que a tornaria factível, enfim, como correta, havendo, entretanto, nesse caso, tantos possíveis princípios de correção quantos eram os posicionamentos teóricos em disputa na ocasião - e também isso comporia, portanto, a matéria da referida decisão, a qual se mostrava, nesses termos, a um só tempo necessária e impossível. Assim, quando Richards conclui em seu livro: "A lição de toda crítica é a de que não temos nada com que contar ao fazer nossas escolhas a não ser nós mesmos"14 - isso não deveria, pois, ser entendido no sentido de uma operação que se dá num vácuo absoluto de regras ou princípios, e sim, ao contrário, num horizonte de possibilidades múltiplas e divergentes de regras ou princípios, em vista das quais se requer, então, uma decisão, sem garantias. A angústia inerente à escolha crítica não seria, pois, a da carência total de princípios, mas, antes, a da abundância de potenciais princípios.

A grande lição daí extraída é, em suma, a de que o verdadeiro ato crítico traduz-se numa dupla decisão a partir de um horizonte de indecidibilidade epistemológico-axiológica, numa dupla decisão, portanto, a um só tempo necessária e impossível, lição essa, entretanto, não passível de transmissão ao modo de uma lição, isto é, ao modo de um conteúdo constatativo-propositivo ensinável como tal, não havendo, pois,
14. RICHARDS, I. A. Practical criticism, p. 328-329. 
15. Cf. Vaihinger (1911/2011).

16. Cf. Suzuki (2002) teoria possível dessa lição, permanentemente irredutível a qualquer teorema. Não obstante, essa dificuldade mostra-se enfrentável sob o aporte da filosofia vaihingeriana do "ficcional", ${ }^{15}$ da qual é factível derivar uma "pedagogia literária do como se". E já que desde Schiller e suas célebres cartas sobre a educação estética do homem a referida "educação estética”, especialmente na forma de uma educação literária, é concebida indissociavelmente de uma educação ética, ${ }^{16}$ então a nova pedagogia literária em questão não deixaria de implicar algo como uma nova pedagogia ética; dir-se-ia: uma pedagogia (est)ética para os novos tempos.

Transcendendo, em suma, o contexto histórico do surgimento do discurso do comparatismo nos estudos literários franceses de fins do século XIX e início do XX, rumo a uma universalidade que se traduz em perspectiva tanto diacrônica quanto sincrônica, o evento comparatista - mise-en-comparation de diferentes perspectivas de comparação crítica implicando uma consciência comparatista - institui-se, pois, como a grande condição de (im)possibilidade do ato crítico, em qualquer tempo e lugar.

\section{REFERÊNCIAS}

ARAÚJO, Nabil (Org.). Diante da lei: uma experiência em Teoria da Literatura. Belo Horizonte: FALE/UFMG, 2010. [Também disponível em: <http://www.letras.ufmg.br/vivavoz/data1/ arquivos/diantedalei-site.pdf> Acesso em: 4 out. 2012.
BARTHES, Roland. Écrire la lecture. In:

Le bruissement de la langue: Essais critiques IV. Paris: Seuil, 1984, p. 33-36. [Ed. bras.: BARTHES, Roland. Escrever a leitura. In : . O rumor da língua. Trad. de Mario Laranjeira. São Paulo : Brasiliense, 1988, p. 40-42.]

DERRIDA, Jacques. La pharmacie de Platon. In: La dissémination. Paris: Seuil, 1972, p. 77-213. [Ed. bras.: DERRIDA, Jacques. A farmácia de Platão. Trad. de Rogério Costa. 3. ed. rev. São Paulo: Iluminuras, 2005.

DERRIDA, Jacques. Ponctuations: le temps de la thèse. In:

Du droit à la philosophie. Paris: Galilée, 1990, p. 439-459.

EISENSTEIN, Sergei. Word and image. In: The film sense New York: Harcourt, Brace \& Company, 1942, p. 3-65. [Ed. bras. EISENSTEIN, Sergei. Palavra e imagem. In: filme. Trad de Teresa Ottoni. Rio de Janeiro: Zahar, 2002, p. 13-50

ISER, Wolfgang. Der Akt des Lesens: Theorie ästhetischer

Wirkung. 4. Aufl. München: Wilhelm Fink, 1994 [1976]. [Ed. bras. ISER, Wolfgang. $\mathbf{O}$ ato da leitura: uma teoria do efeito estético. Trad. de Johannes Kretschmer. 2. v. São Paulo: 34, 1996 (v. 1)/1999 (v. 2).]

JARRETT, Michael. Drifting on a read: jazz as a model for writing. Albany (NY): State University of New York Press, 1999

PIETTRE, Bernard. Philosophie et science du temps. 2. ed. cor. Paris: PUF, 1996. [Ed. bras.: PIETTRE, Bernard. Filosofia e ciência do tempo. Bauru (SP): Edusc, 1997.

EM TESE

BELO HORIZONTE

v. 19

N. 2

AG0.-OUT. 2013

ARAÚJO. Textos-leitura, efeito de montagem: 0 evento comparatista

P. $238-251$ 
RICHARDS, I. A. Practical criticism: a study of literary

judgement. New York: Harcourt, Brace \& World, 1956 [1929].

[Ed. bras.: RICHARDS, I. A. A prática da crítica literária. Trad.

de Almiro Pisetta e Lenita Maria R. Esteves. São Paulo: Martins

Fontes, 1997.

SUZUKI, Márcio. O belo como imperativo. In: SCHILLER,

Friedrich. A educação estética do homem numa série de cartas

4. ed. Trad. de Roberto Schwarz e Márcio Suzuki. São Paulo:

lluminuras, 2002, p. 7-15.

VAIHINGER, Hans. Die Philosophie des Als Ob: System der

theoretischen, praktischen, und religiösen Fiktionen der Menschhe

auf Grund eines idealistischen Positivismus. 7 und 8. Aufl. Leipzig

Feliz Meiner, 1922 [1911]. [Ed. bras.: VAIHINGER, Hans. A filosofia

do como se: sistema das ficções teóricas, práticas e religiosas

da humanidade, na base de um positivismo idealista. Trad. de

Johannes Kretschmer. Chapecó (SC): Argos, 2011.] 